J. Clin. Chem. Clin. Biochem.

Vol. 26, 1988 , pp. $345-348$

(C) 1988 Walter de Gruyter \& Co. Berlin $\cdot$ New York

\title{
Methylcitric Acid Determination in Amniotic Fluid by Electron-Impact Mass Fragmentography
}

\author{
By R. E. Kretschmer and C. Bachmann \\ Chemisches Zentrallabor der Universitätskliniken, Inselspital, Bern, Schweiz
}

(Received October 9, 1987/February 15, 1988)

Summary: Methylcitric acid, a metabolite of abnormal propionyl-CoA metabolism, is elevated in amniotic fluid when the fetus is affected with propionic acidaemia or methylmalonic aciduria. We developed a method for quantifying methylcitric acid in amniotic fluid by solid-phase extraction, derivatisation to the $t$-butyldimethylsilylester, and gas chromatography-mass spectrometry with electron-impact ionisation, using the deuterated analogue of methylcitric acid as an internal standard. The main advantages are a good sensitivity, simple sample preparation, and feasibility on instruments equipped with mass specific detectors.

\section{Introduction}

The prenatal diagnosis of propionic acidaemia (propionyl CoA carboxylase ${ }^{1}$ ) deficiency), and of the methylmalonic acidurias (methylmalonylCoA mutase ${ }^{1}$ ) deficiency and cobalamine disorders) can be rapidly established by quantifying methylcitrate in the amniotic fluid obtained at the 15-16th week of pregnancy $(1,2)$ or perhaps even earlier (L. Sweetman, personal communication). The method of choice for the quantification of methylcitrate (2-hydroxy-1,2,3butanetricarboxylic acid), normally present at concentrations below $1 \mu \mathrm{mol} / 1$, is nowadays gas chromatography mass spectrometry (GC-MS) with stable isotope dilution.

A frequently used derivatisation procedure for gas chromatography of organic acids, and particularly methylcitrate, is silylation (3). Upon electron impact ionisation (EI) with $70 \mathrm{eV}$, high mass fragments of the trimethylsilyl derivatives are of low abundance and the specifity of lower mass fragments is reduced. In order to circumvent the resulting low sensitivity, chemical ionisation methods have been applied $(1,3)$.

\footnotetext{
1) Enzymes: Methylmalonyl-CoA decarboxylase (PropionylCoA carboxylase), EC 4.1.1.41; Methylmalonyl-CoA mutase, EC 5.4.99:2.
}

Another possibility would be EI with lower ionisation energy, which however needs more expensive mass spectrometers.

Since GC-MS instruments limited to fixed electron impact ionisation are more readily available, we developed a method suitable for GC-MS with EI, using $t$-butyl-dimethylsilyl derivatives, which offer the advantage of a high yield of heavy and specific (M-57) fragments.

\section{Materials and Methods \\ Standards, chemicals}

Chloroform and $t$-amylalcohol (both p. a.), $\mathrm{HCl}$, ammonia and Extrelute-3 columns were obtained from Merck (Zürich, Switzerland) and used without further purification.

Tricarballylic acid was from Fluka (Buchs, Switzerland), Nmethyl-N-( $t$-butyldimethylsilyl)trifluoroacetamide from Pierce (Kontron, Zürich, Switzerland).

The deuterated analogue of methylcitric acid was synthesised according to Beach et al. (4). Diethyl 1,3-acetone-dicarboxylate was reacted with $d_{3}$-methyliodide (Merck, isotopic purity $99.88 \%$ or better) to produce diethyl-2-methyl-3-oxoglutarate. After a cyanohydrin reaction the product was hydrolysed with concentrated $\mathrm{HCl}$ to methylcitric acid. Non-deuterated methylcitric acid was obtained by the same procedure, using unlabeled methyliodide (Merck). The described acids were obtaincd 
as a mixture of stereoisomers; however, no attempt was made to separate them since the same two isomers appear in about equal amounts in the amniotic fluid, and are readily resolved in the GC-MS-system.

\section{Samples}

Amniotic fluid samples were obtained from normal pregnancies, from patients at risk for fetal neural tube defects and from patients at risk for propionic acidaemia or methylmalonic aciduria, mainly at the 16 th -19 th week of gestation. The specimens were centrifuged and the supernatant stored at $-20^{\circ} \mathrm{C}$ until processed.

\section{Standard procedure}

To $1 \mathrm{ml}$ sample were added: $20 \mathrm{nmol}$ of deuterated methylcitric acid in $100 \mu \mathrm{l}$ water, $100 \mathrm{nmol}$ of tricarballylic acid in $100 \mu \mathrm{l}$ water (as an internal standard for control of effective silylation), and $1.8 \mathrm{mmol} \mathrm{HCl}(300 \mu \mathrm{l}$ of $6 \mathrm{~mol} / \mathrm{l} \mathrm{HCl})$.

As a standard, $1 \mathrm{ml}$ of water containing $20 \mathrm{nmol}$ of methylcitric acid was treated as a sample.

The pretreated samples and the standard probe were adjusted with $1300 \mu$ l of water to a total volume of $2800 \mu$ land absorbed on an Extrelut-3 column for 10 minutes. The elution was performed with $15 \mathrm{ml}$ of a mixture of chloroform and $t$-amylalcohol $(1+1$, by vol.), into conical 20 -ml flasks containing $2.4 \mathrm{mmol}$ of ammonium hydroxide solution $(800 \mu \mathrm{l}, 3.0 \mathrm{~mol} / \mathrm{l})$, and mixed briefly on a vortex mixer.

The whole eluates were evaporated to dryness under a stream of nitrogen in a waterbath at $50^{\circ} \mathrm{C}$. Then $150 \mu \mathrm{l}$ of $\mathrm{N}$-methyl$\mathrm{N}$-( $t$-butyldimethylsilyl)trifluoroacetamide were added to the dry residues, and the flasks were carefully stoppered and maintained at $70^{\circ} \mathrm{C}$ for $1 \mathrm{~h}$. After cooling, $4 \mu \mathrm{l}$ of the solution were injected into the GC-MS system.

\section{Gas chromatography-mass spectrometry}

A Hewlett-Packard HP5990 GC-MS system with floppy disc software was used. For gas chromatography, a $30 \mathrm{~m}$ capillary column of Durabond DB-5 ( $\mathrm{J}+\mathrm{W}$ Scientific, Rancho Cordova, CA, USA), $0.32 \mathrm{~mm}$ ID, coated with $0.25 \mu \mathrm{m}$ SE54, chemically bonded, was installed in the GC-MS system. The injector temperature was $250^{\circ} \mathrm{C}$. The carrier gas was helium at $3 \mathrm{ml} / \mathrm{min}$. The temperature was programmed for 3 minutes at $200^{\circ} \mathrm{C}$, followed by heating at $8{ }^{\circ} \mathrm{C} /$ minute to $270^{\circ} \mathrm{C}$. Under these conditions, the retention times for the methylcitric acid isomers were 7.4 and 7.6 minutes, respectively. Effluent was transferred to the MS by a jet separator, and ionisation was by electronimpact $(70 \mathrm{eV})$.
The effectiveness of silylation was controlled by monitoring the peak area of the tricarballylic derivative which in our experience is sensitive to interferences. The mass fragmentography (dwell times $50 \mathrm{~ms}$ ) was performed so as to record the abundances of ions (M-57) of the methylcitrate and $d_{3}$-methylcitrate derivatives, $\mathrm{m} / \mathrm{z} 605$ and $\mathrm{m} / \mathrm{z} 608$, respectively. The integration was done using the standard software of the isystem. All the calculations were made by adding the areas of the two peaks of the methylcitrate stereoisomer derivatives. Owing to the good linearity of the isotopic dilution standard curve of the ratio of $\mathrm{m} / \mathrm{z} 605$ to $\mathrm{m} / \mathrm{z} 608$, further calculations of the samples were made using only one standard ratio.

\section{Results}

Mass spectra of deuterated and nondeuterated methylcitrate are depicted in figure 1 . The intra-series precision of the method amounted to $1.9 \% \mathrm{CV}$ $(\mathrm{n}=9)$ measured at a concentration of $2.53 \mu \mathrm{mol} / \mathrm{l}$, the day to day precision was $3.6 \% \mathrm{CV}(\mathrm{n}=12)$, with a mean of $2.50 \mu \mathrm{mol} / 1$. The recoveries were tested by adding increasing amounts of methylcitrate to $1 \mathrm{ml}$ amniotic fluid (tab. 1). While recoveries of $105 \%$ were found at the lowest concentration, they systematically decreased to $88 \%$ at $30 \mathrm{nmol}$ added.

The limit of detection was lower than $50 \mathrm{nmol} / \mathrm{l}$.

The time required for performing the analysis was about $6 \mathrm{~h}$ for 8 samples.

Tab. 1. Recovery of nonlabelled methylcitrate added to $1 \mathrm{ml}$ of amniotic fluid:

\begin{tabular}{lll}
\hline $\begin{array}{l}\text { Standard added } \\
\text { (nmol) }\end{array}$ & $\begin{array}{l}\text { Observed } \\
\text { concentration } \\
(\mu \mathrm{mol} / \mathrm{l})\end{array}$ & Recovery \\
\hline 0 & 0.43 & $(\%)$ \\
1.11 & 1.59 & - \\
1.67 & 2.21 & 105.0 \\
3.33 & 3.84 & 107.0 \\
8.88 & 8.86 & 102.3 \\
16.6 & 16.2 & 95.0 \\
33.3 & 29.6 & 94.6 \\
\hline
\end{tabular}

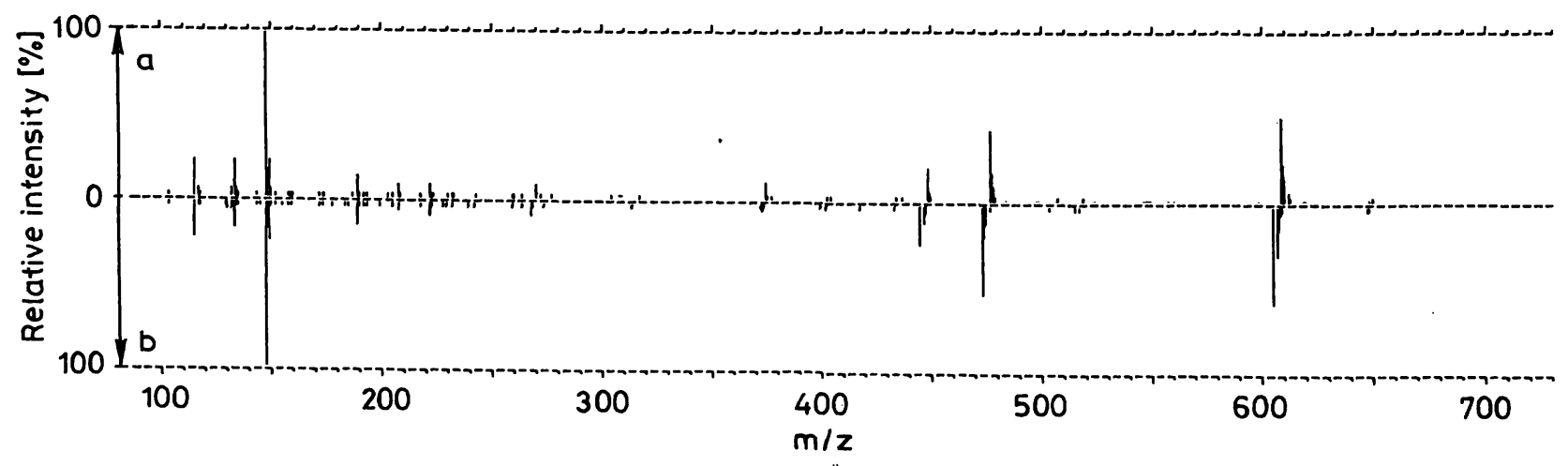

Fig. 1. Mass spectra of the deuterated (a) and the nondeuterated methylcitrate derivatives (b; for conditions see text). 


\section{Reference values}

Methylcitrate was readily detected in all amniotic fluid samples. The distribution of the data from samples obtained at 14-19 wecks of gestation was tested for normality by the Kolmogoroff-Smirnov and the $\chi^{2}$ tests. No significant deviation from a Gaussian distribution was found. The upper limit of the reference range can thus be estimated at $530 \mathrm{nmol} / \mathrm{l}$ (tab. 2).

Tab. 2. Reference values for methylcitrate in amniolic fluid:

\begin{tabular}{ll}
\hline $14 \mathrm{th}-19 \mathrm{th}$ weck of gestation: & Range $110-480 \mathrm{nmol} / \mathrm{l}$ \\
$\mathrm{n}=31$ & Median value $350 \mathrm{nmol} / \mathrm{l}$ \\
& Mean $\pm \mathrm{SD}:$ \\
& $340 \pm 94 \mathrm{nmol} / \mathrm{l}$ \\
$31 \mathrm{st}-36 \mathrm{st}$ week of gestation: & $550,580,710,600 \mathrm{nmol} / \mathrm{l}$ \\
$\mathrm{n}=4$ & \\
\hline
\end{tabular}

In 4 samples taken at the 31 st to the 36 th weeks of gestation for testing foetal lung maturity, we measured a significant elevation (Wilcoxon test, $\mathrm{p}<0.01$ ) of the methylcitrate concentration compared with the samples obtained at 14-19 weeks of gestation; the median was at $590 \mathrm{nmol} / \mathrm{l}$ with a range of $550-710$ nmol/l.

The method proved to be useful for the detection of patients affected as shown in table 3 . Using the same samples, parallel determinations were done by $L$. Sweetman in San Diego with chemical ionisation GCMS; the results were practically identical.

Tab. 3. Methylcitrate in amniotic fluid of patients at risk (nmol/l):

\begin{tabular}{lll}
\hline Non-affected: & $\mathrm{n}=3:$ & 430,$290 ; 250(270)^{\mathrm{a}}$ \\
Affected $:$ & $\mathrm{n}=2:$ & $11500 ; 6800(6600)^{\mathrm{u}}$ \\
\hline
\end{tabular}

"Values obtained in parallel in a reference laboratory

b Propionyl-CoA carboxylase deficiencies

\section{Discușsion}

The use of Extrelute for the sample preparation for GC-MS is well established $(5,6)$ in our laboratory. To extract organic acids, the sample has to contain an amount of $\mathrm{HCl}$ corresponding to the volume of the column rather than to the sample volumc; we observed a strong decline in the extraction efficiency when less than $250 \mu \mathrm{l}$ of $\mathrm{HCl}(6 \mathrm{~mol} / \mathrm{l})$ were added to the sample.

An adequate silylation could not be obtained at room temperature, even after $20 \mathrm{~h}$ rcaction time. The same reagent with $t$-butyldimethylsilylchloride $(10 \mathrm{~g} / \mathrm{l})$, or with the addition of acetonitrile, did not lead to better results, but complete derivatisation was achieved by heating at $70^{\circ} \mathrm{C}$ for at least 40 minutes.

This method illustrates well the advantages of using GC-MS together with isotopic dilution and a solidliquid extraction method. The sensitivity and the selectivity of the GC-MS, together with the dcuterated internal standard, which also acts as a carrier, allow a fast and simple specimen preparation.

The methylcitrate concentration in amniotic fluid of patients with inherited defects of propionate melabolism is much higher than that of controls. Thus the systematic decrease in recovery of high concentrations is not a serious drawback for diagnosis. The use of a standard curve with several concentrations (including high ones) could improve the accuracy, but is more time consuming.

The antenatal diagnosis of inherited metabolic disorders by the quantification of critical metabolites in amniotic fluid is now well documented $(2,3,7)$; if possible, it is performed in parallel with the determination of enzymatic activity in cultured foetal cells obtained from amniotic fluid. The metabolite determination, however, does not have the disavantage of the time delay of tissue culture.

The present method uses simple sample preparation, and does not need especially sophisticated instrumentation. It thus could be used by a large number of clinical laboratories interested in inborn errors. Nevertheless we would recommend - as for other analyses used for prenatal diagnosis - that the analyses or enzyme determination be performed in parallel in an independent laboratory for confirmation, because of the prognostic implications of the results.

\section{Acknowledgement}

We are grateful to the Kamillo-Eisner Stiftung for granting the GC-MS systcm. 


\section{References}

1. Naylor, G., Sweetman. L., Nyhan, W. L., Hornbeck, C., Griffiths, J., Mörch, L. \& Brandänge, S. (1980) Clin. Chim. Acta 107, 175-183.

2. Sweetman, L. (1984) J. Inher. Metab. Dis. 7, Suppl. 1, 18.

3. Fensom, A. H., Benson, P. F., Chalmers, R. A., Tracey, B. M., Watson, D., King, G. S., Pettit, B. R. \& Rodeck, C. H. (1984) J. Inher. Metab. Dis. 7, Suppl. 2, 127.
4. Beach, R. L., Aogaichi, T. \& Plaut, G. W. (1977) J. Biol. Chem. 252, 2702-2709.

5. Bachmann, C., Bühlmann, R. \& Colombo, J. P. (1984) J. Inher. Metab. Dis. 7, Suppl. 2, 126.

6. Bachmann, C. (1987) Enzyme 38, 233-241.

7. Jakobs, C. A. (1983) Contribution to the prenatal diagnosis of inherited metabolic disorders; analysis of metabolites in amniotic fluid. Thesis. Úniversity of Utrecht.

Dr. R. Kretschmer Chemisches Zentrallabor der Universitätskliniken Inselspital CH-3010 Berne 